\title{
Reestudo de Anthomyces brasiliensis em Caesalpinia echinata no Brasil*
}

\author{
Cristiane F. L. Araújo ${ }^{1 * *}$, Karina P. Gramacho² \& José L. Bezerra ${ }^{2 * *}$ \\ ${ }^{1}$ Universidade Estadual de Santa Cruz , Rodovia Ilhéus-Itabuna, km 16, CEP 45650-000, BA, e-mail: \\ lopesdearaujo@hotmail.com; ²CEPLAC/CEPEC/SEFIT, Cx. Postal 07, CEP 45600-000, Itabuna, BA
}

(Aceito para publicação em 24/06/2005)

Autor para correspondência: Cristiane Ferreira Lopes de Araújo

ARAÚJO, C.F.L., GRAMACHO, K.P. \& BEZERRA, J.L. Reestudo de Anthomyces brasiliensis em Caesalpinia echinata no Brasil. Fitopatologia Brasileira 30:510-515. 2005.

\section{RESUMO}

O fungo Anthomyces brasiliensis foi descrito em 1899 no Rio de Janeiro causando ferrugem em Caesalpinia sp. ou Piptadenia sp. sendo redescoberto no ano de 2001 em Porto Seguro, Bahia, causando a ferrugem do pau-brasil (Caesalpinia echinata). Na descrição original de A. brasiliensis estão descritos apenas télios e urédios, não tendo sido observada a existência de espermogônios e écios. Folhas com pequenas lesões necróticas nos folíolos foram coletadas de mudas e plantas adultas de pau-brasil na Estação Experimental Pau-Brasil (CEPLAC) no município de Porto Seguro, Bahia. Folíolos frescos e herborizados foram examinados ao microscópio estereoscópico, sendo efetuadas raspagens e cortes histológicos, os quais foram analisados em microscópios e composto, e eletrônico de varredura para caracterização, mensuração e fotomicrografias das estruturas observadas. Nos estudos conduzidos no material coletado na Bahia foram encontrados espermogônios do grupo VI, tipo 7, característicos da família Raveneliaceae à qual pertence o gênero Anthomyces. Os espermogônios de A. brasiliensis são subcuticulares, de contorno circular, aplanados e medem 70-100 x 30-56 $\mu \mathrm{m}$, com espermacióforos hialinos, basais, cilíndricos, agrupados em forma de paliçada, medindo 12-14 x 2-3 $\mu$ m. Os espermácios são hialinos, unicelulares, lisos, medindo 3-4 x 2-3 $\mu \mathrm{m}$. Pústulas acompanhadas por espermogônios foram interpretadas como écios uredinóides, característicos da família Raveneliaceae. Estas estruturas têm aspecto de pústulas alargadas, sem perídio definido, mostrando-se maiores que os télios e os urédios, medindo 200-700 $\mu \mathrm{m}$ diâmetro e 100-110 $\mu \mathrm{m}$ de altura, com eciósporos idênticos aos urediniósporos, medindo de 22-24 x 18-22 $\mu \mathrm{m}$. Desta forma, A. brasiliensis passa a ser definida como uma ferrugem macrocíclica, autóica, contendo os estádios de 0 a IV.

Palavras-chave adicionais: ferrugem, taxonomia, ciclo vital, micologia.

\begin{abstract}
Restudy of Anthomyces brasiliensis on Caesalpinia echinata in Brazil

The fungus, Anthomyces brasiliensis described in 1899 in Rio de Janeiro causing rust on Caesalpinia sp. or Piptadenia sp., was rediscovered in 2001 in Porto Seguro, Bahia, Brazil on Caesalpinia echinata. In the original description only telia and uredia were described, but spermogonia or aecia was not observed. Leaves with small necrotic lesions were collected from seedlings and trees of $C$. echinata at Pau-Brasil Experimental Station (CEPLAC) in the municipality of Porto Seguro, Bahia. Material from fresh and dried leaflets was examined under dissecting and compound microscopes. Micrographs were obtained using the compound and scanning electron microscopes. Group VI (type 7) spermogonia were found for the first time on the material collected in Bahia. They were subcuticular, round in outline, flattened, 70-100 x 30-56 ì m with spermatiophores hyaline, cylindrical, grouped in palisade, 12-14 x 2-3 ì m. Spermatia ellipsoid, hyaline, smooth, 3-4 x 23 ì m. Pustules associated with spermogonia were interpreted as uredinoid aecia. They are larger than uredia and telia, 200700 ì m wide. Aeciospores are similar to urediniospores, measuring 22-24 x 18-22 ì m. Thus, A. brasiliensis can now be defined as a macrocyclic, autoecious rust containing 0 to IV states.
\end{abstract}

Additional keywords: rust, taxonomy, biological cycle, micology.

\section{INTRODUÇÃO}

O pau-brasil (Caesalpinia echinata Lam.) Fabaceae semidecídua, heliófita, com casca pardo acinzentada, ou pardo-rosada nas partes descascadas, e cerne vermelho (Lorenzi, 1992) é a árvore símbolo da nação brasileira. Tratase hoje de uma espécie ameaçada de extinção (IBAMA, 1992) originária da floresta pluvial Atlântica, ocorrendo do Estado do Rio Grande do Norte até o Rio de Janeiro, ao longo de

\footnotetext{
* Parte da dissertação de mestrado da primeira autora. UESC (2004).

** Bolsistas CNPq
}

$3000 \mathrm{~km}$. O pau-brasil tem um papel muito importante no ecossistema, pois, encontra-se freqüentemente coberto por orquídeas e outras epífitas.

Poucos patógenos foram registrados sobre a espécie. Mendes et al. (1998) citam neste hospedeiro os fungos Ganoderma sp. e Pestalotiopsis maculans (Corda) Nag Raj (1985). Grandi \& Silva (2003) estudaram os seguintes hifomicetos na serrapilheira de Pau-Brasil: Chaetendophragmia fasciata Castañeda, Henicospora minor P. M. Kirk \& B. Sutton, Pseudodictyosporium wauense Matsushima e Sporidesmium filiferum Pirozynsky. Dietel (1899) encontrou 
uma ferrugem em folhas de Leguminosae (Caesalpinia sp. ou Piptadenia sp.) no Rio de Janeiro a qual foi descrita sob o nome de Anthomyces brasiliensis Dietel. O gênero é monotípico tendo como espécie tipo A. brasiliensis Dietel (Kirk et al., 2001; Cummins \& Hiratsuka, 2003). Em fevereiro de 2001, foram observadas sobre mudas de paubrasil em viveiro da Estação Ecológica de Pau-Brasil, da CEPLAC, município de Porto Seguro, lesões necróticas nas folhas. Posteriormente, o mesmo tipo de lesão foi observado em folhas de plantas adultas de mais de dez anos. Em exames efetuados detectou-se sobre as lesões, a presença de urédios e télios, de tamanho reduzido, sendo os teliósporos característicos da espécie A. brasiliensis. A morfometria desta espécie é compatível com os espécimes encontrados na Bahia sobre C. echinata que foi reportado como um novo hospedeiro de A. brasiliensis (Bezerra \& Costa, 2001).

Este trabalho apresenta uma nova descrição da espécie com base em observações de fases do ciclo vital de $A$. brasiliensis anteriormente desconhecidas. Além disso, foram feitos estudos sobre a sazonalidade das suas fases em paubrasil.

\section{MATERIAL E MÉTODOS}

\section{Coleta}

Foram realizadas coletas nos municípios de Porto Seguro, Pau-Brasil, Uruçuca, Ilhéus e Itajuípe, no estado da Bahia e no município de São Lourenço da Mata, em Pernambuco. O material coletado consistia de folhas e folíolos com manchas necróticas, retirados de mudas enviveiradas e da ramagem de plantas adultas, bem como de mudas e plantas jovens nascidas espontaneamente na mata, ao lado de plantas adultas. O material exibindo manchas foi prensado entre folhas de papel de jornal e desidratado em secador ventilado, aproximadamente, a $60{ }^{\circ} \mathrm{C}$. Após este procedimento foi acondicionado em exsicatas e depositado em herbário. Na Estação Experimental Pau-Brasil, no município de Porto Seguro, coletou-se material ao longo do ano visando acompanhar o desenvolvimento da ferrugem.

\section{Microscopia ótica}

Para observação ao microscópio ótico foram utilizados materiais frescos e herborizados. Lâminas de raspagem foram feitas com ácido lático ou lactofenol, com ou sem corante azul-de-algodão. Cortes histológicos manuais foram montados de forma idêntica entre lâmina e lamínula. As observações das estruturas do fungo foram efetuadas em um microscópio Leica DMLS, nas objetivas de 40 e 100 vezes de aumento, sendo as imagens registradas em fotos convencionais ou digitalizadas e capturadas em computador utilizando-se o “software Capkit”. Observações detalhadas dos sintomas e sinais foram efetuadas em um microscópio estereoscópico Olympus, e as imagens digitalizadas capturadas conforme descrição anterior.

No preparo de cortes mais delgados, foram adotados os seguintes procedimentos: o material herborizado foi inicialmente hidratado em etanol a $10 \%$ e tween 20 a $0,1 \%$ por $24 \mathrm{~h}$, e em seguida congelados a $-21^{\circ} \mathrm{C}$. Os cortes histológicos foram efetuados em micrótomo de congelamento, marca Micron HM505E, e montados, de forma semipermanente em lâminas de vidro para observações e microfotografias em microscópio ótico. No preparo das lâminas semipermanentes, os cortes selecionados eram transferidos para lâminas contendo gotas do corante lactoglicerol/azul de algodão ou as secções eram colocadas em solução saturada de cloral hidratado, quando se pretendia ver os poros germinativos dos esporos. Na observação de detalhes morfológicos ou ontogênicos dos esporos, foi utilizado o corante de Bruzesse \& Hassan (1983), sem fenol, preparado com a seguinte composição: $40 \mathrm{~g}$ de cloral hidratado, $15 \mathrm{ml}$ de clorofórmio, $125 \mathrm{ml}$ de ácido lático a 90\%, $300 \mathrm{ml}$ de etanol a 95\% e 0,6 g de azul de anilina. Em seguida, as lâminas foram seladas com esmalte de unha, etiquetadas e armazenadas para estudo.

No exame do material foram também utilizados cortes histológicos em tecidos embebidos em parafina onde os fragmentos foram fixados, desidratados em uma série de álcool butílico terciário (50 a 100\%) e embebidos em parafina (ponto de fusão $56,5^{\circ} \mathrm{C}$ ), após serem seccionados (5 a $12 \mu \mathrm{m}$ de espessura) em um micrótomo rotativo. As secções foram fixadas em lâminas de microscopia com o adesivo de Haupt, após serem desengorduradas em três trocas de xilol 100\%, e passadas através de uma série de xilol/álcool etílico absoluto (AEA) (1:1), AEA absoluto, AEA 70\% e as secções foram coradas com Pianeze IIIB (Vaughan, 1914; Gramacho, 1999).

\section{Microscopia eletrônica de varredura}

No exame de tecidos infetados e de estruturas fúngicas ao microscópio eletrônico de varredura (MEV), foram efetuados cortes em tecidos frescos ou hidratados, medindo $0,5 \times 0,8 \mathrm{~cm}^{2}$, os quais foram transferidos para recipientes contendo uma solução fixadora de glutaraldeído a 3\% em tampão cacodilato de sódio 0,05 M, pH 6,9. Os recipientes foram tampados e mantidos em geladeira a $4^{\circ} \mathrm{C}$, por $12 \mathrm{~h}$ e, em seguida, efetuadas cinco lavagens sucessivas do material com a mesma solução tampão. Após a lavagem, os cortes foram tratados com tetróxido de ósmio (OsO4) a 1\% em tampão de cacodilato, permanecendo em refrigerador a 4 ${ }^{\circ} \mathrm{C}$, por $4 \mathrm{~h}$ e, em seguida, submetidos a uma nova série de cinco lavagens com a solução tampão (Souza, 1998). A seguir o material foi desidratado em uma série aquosa contendo 30\%, 50\%, 70\%, 85\%, 95\% e 100\% de acetona. Os fragmentos permaneceram em cada concentração por 10 a 20 min, sendo que a última solução foi trocada três vezes. Em seguida, procedeu-se a secagem do material, ao ponto crítico, em um aparelho de secagem CPD-030 Balzers (Baltec, Fuerstentum, Liechtenstein), utilizando-se $\mathrm{CO}_{2}$ líquido. Os fragmentos de tecidos secos foram presos a suportes metálicos utilizando-se pasta condutiva de prata. Os suportes contendo o material foram então cobertos com uma fina camada de ouro por meio de pulverização catódica em aparelho marca Balzers, modelo SCD50 por 140 s. 
Observações foram efetuadas ao microscópio eletrônico de varredura marca Jeol, modelo JSM840-A (Jeol Ltd, Tóquio, Japão), com acelerações de 5 e $10 \mathrm{KV}$ e distância de trabalho de $20 \mathrm{~mm}$ e obtidas fotografias das várias estruturas do fungo.

Como critérios morfológicos utilizados na identificação taxonômica foram considerados a espessura e ornamentação da parede, cor, tamanho e forma dos teliósporos e urediniósporos, características dos pedicelos dos teliósporos e número e posição dos poros germinativos em urediniósporos. Paráfises, forma dos esporos, sintomas e sinais no hospedeiro, especificidade pelo hospedeiro, foram características adicionais que também ajudaram na identificação da espécie. Os resultados obtidos foram então comparados com a descrição da espécie na literatura. O espécime tipo de A. brasiliensis depositado no Arthur's Herbarium da Universidade de Purdue foi disponibilizado para efeito de comparação.

\section{RESULTADOS}

\section{Descrição do patógeno}

Lesões a princípio punctiformes, tornando-se circulares a irregulares, castanhas, com um halo amarelado, dispersas, às vezes coalescentes, tornando-se necróticas com o passar do tempo, medindo 1-6 mm de diâmetro. Espermogônios subcuticulares, anfígenos, de contorno circular, aplanados, grupo VI, tipo 7, (Cummins \& Hiratsuka, 2003) (Figura 1), medindo 70-100 ìm de diâmetro e 30-56 ìm de altura, com espermacióforos basais, hialinos, cilíndricos, dispostos em paliçada, medindo 12-14 x 2-3 ìm; espermácios hialinos, unicelulares, elipsóides, lisos, 3-4 x 2-3 ìm. Écios uredinóides formados em manchas foliares grandes, necróticas, supostamente resultantes de infecções primárias dos basidiósporos, geralmente hipófilos, subepidérmicos, irrompentes, amarelos, usualmente maiores e mais espalhados que os urédios, 200-700 ìm de diâmetro e 100-110 ìm de altura (Figura 2); eciósporos ovóides a elipsóides, subhialinos a amarelo-claros, equinulados, unicelulares, 22-24 x 18-22 ìm, com 2-3 poros germinativos equatoriais (Figura 2B); epispório 1,5-2 ìm de espessura. Paráfises periféricas, curvadas para dentro dos écios, não septadas, de paredes espessas e lúmen estreito, 8-12 ìm de diâmetro. Urédios hipófilos, subepidérmicos, irrompentes, dispersos, pustuliformes, amarelos, parafisados, 150-210 ì m de diâmetro e 40-100 ìm de altura (Figura 3A, 3B ); micélio imerso extenso, formado de hifas flexuosas, septadas, ramificadas, intra e intercelulares, 3-4 ìm de diâmetro, estendendo-se da epiderme foliar inferior à superior (Figura 4C). Urediniósporos idênticos aos eciósporos (Figura 3C, CD, 3E); haustórios unicelulares, hialinos, oblongos, formados nas células subepidérmicas (Figura 4A, 4B). Paráfises periféricas em sua maioria, cilindro-clavadas, fortemente arqueadas, de paredes espessas e lúmen estreito, unidas duas a duas na base, 4-6 ìm de diâmetro. Télios anfígenos, subepidérmicos, castanhos, protuberantes, pustuliformes, dispersos, parafisados, 220-240 ìm de
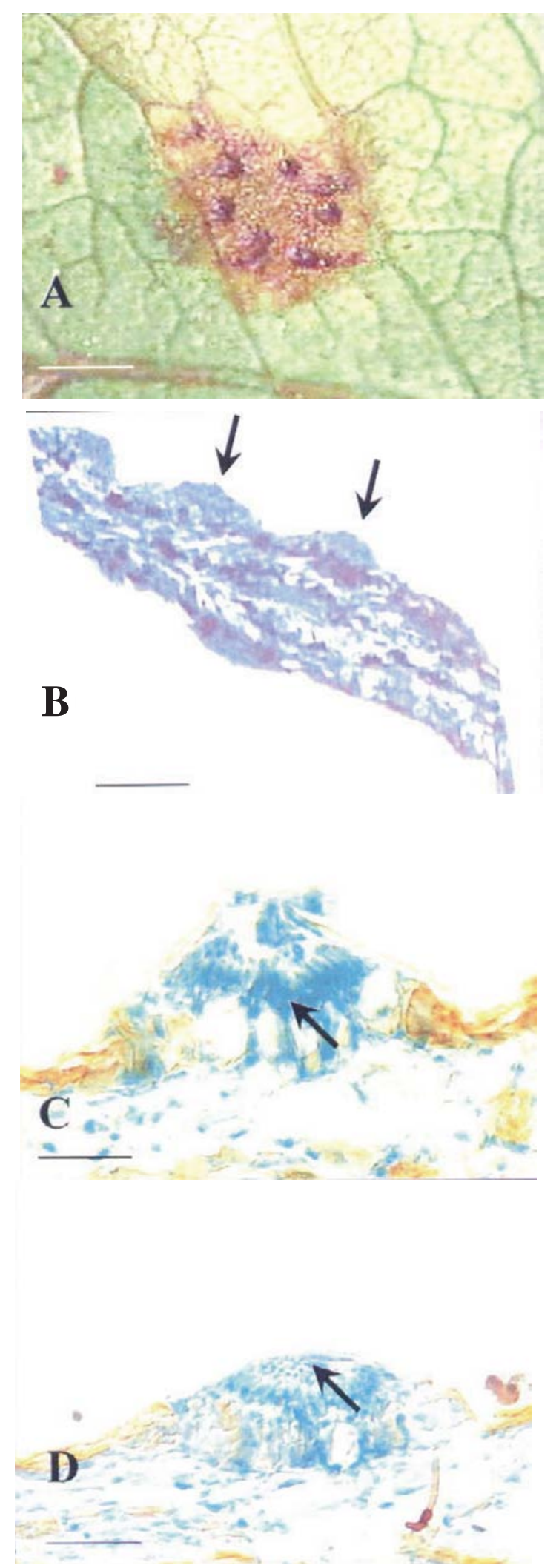

FIG. 1 - Anthomyces brasiliensis. A) Espermogônios ao microscópio estereoscópico; B) Espermogônios anfígenos em secção longitudinal; C) Espermogônio subcuticular com espermacióforos em paliçada (seta); D) Espermogônio contendo espermácios (seta). Barras: A = 200 ìm; B = 100 ìm; C e D = 20 ìm. 


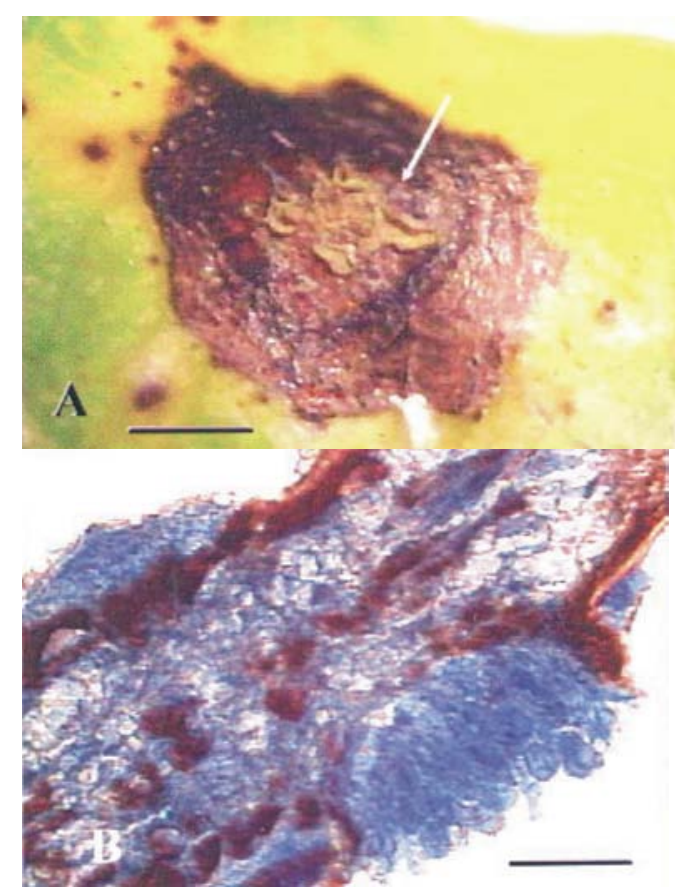

FIG. 2 - Anthomyces brasiliensis. A) Supostos écios uredinóides ao microscópio estereoscópico; B) Supostos écios uredinóides em secção longitudinal; C) Supostos écios uredinóides subcuticulares, paráfise curvada para dentro (ponta de seta). Barras $\mathrm{A}=100$ ìm; $\mathrm{B}=70$ ìm; $\mathrm{C}=70$ ìm.

diâmetro e 160 ìm de altura (Figura 5A, 5B, 5C); Teliósporos unicelulares, castanhos, lisos, firmemente unidos lateralmente formando um cacho radial com três ou mais esporos 40-48 ìm de diâmetro (Figura 6A e D), com um poro germinativo apical em cada teliósporo (Figura 6C); pedicelos simples 6-9 ìm de diâmetro e 40-100 ìm de comprimento (Figura 6A e D), com células apicais em igual número ao dos esporos medindo 12-18 ìm de comprimento e 4-8 ìm de largura; micélio imerso idêntico ao dos urédios. Paráfises semelhantes às dos urédios, porém, menos abundantes. Soros mistos contendo urediniósporos e teliósporos foram também observados.

\section{Material examinado}

BRASIL, BAHIA: Município de Porto Seguro, Estação Experimental Pau-Brasil (CEPLAC), 14.07.2003, 05.12.2003, 19.03.2004, 21.01.2004.

BRASIL, PERNAMBUCO: Município de São Lourenço da Mata, Estação Ecológica de Tapacurá, 07.2003.

Arthur's Herbarium, Universidade de Purdue, Indiana, USA, F2190, F2189, F18301, N2526.

\section{Ciclo Vital}

Como muitas das ferrugens tropicais, $A$. brasiliensis não possuía seu ciclo de vida completamente esclarecido. Dietel (1899) na sua descrição original descreveu apenas télios e urédios não tendo observado espermogônios e écios. Nos estudos conduzidos no material coletado na Bahia foram encontrados espermogônios do grupo VI, tipo 7, característicos da família Raveneliaceae na qual se situa o gênero Anthomyces. Soros acompanhados por espermogônios, foram interpretados como supostos écios uredinóides, também característicos da família Raveneliaceae. Desta forma, A. brasiliensis passa a ser descrita como uma ferrugem macrocíclica autóica, embora os basidiósporos não tenham sido observados.

Na Estação Experimental de Pau-Brasil os diferentes estádios espóricos do fungo foram observados nas seguintes épocas: espermogônios a partir de julho; écios uredinóides a

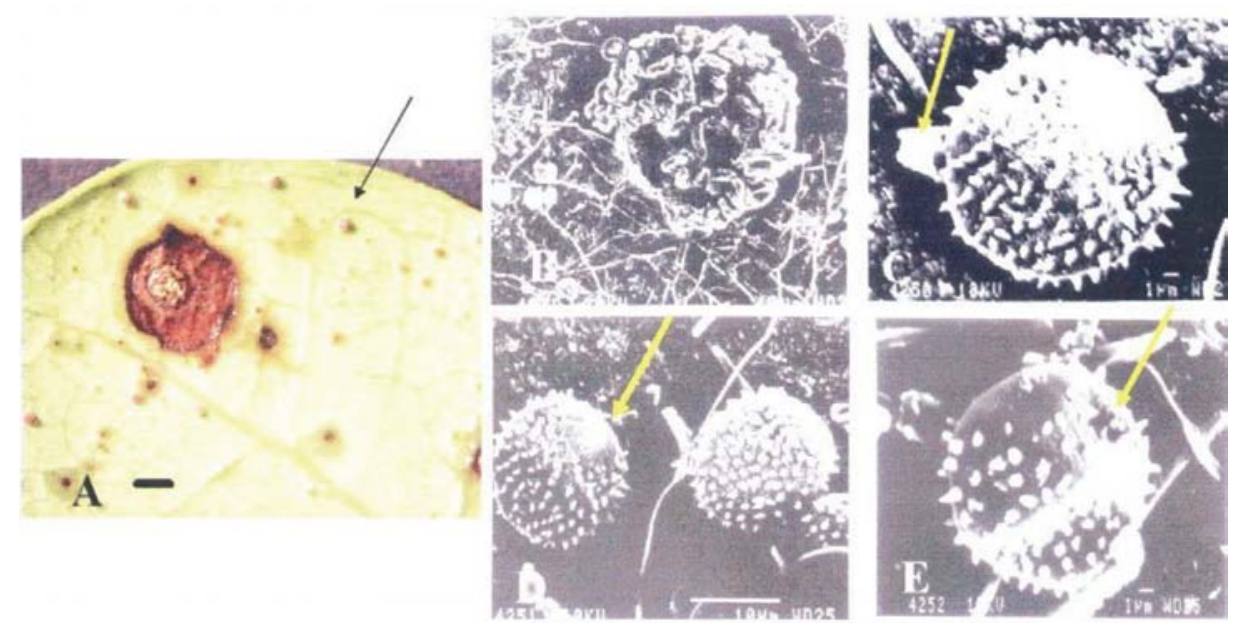

FIG. 3 - Anthomyces brasiliensis. A) Urédios ao microscópio estereoscópico (seta); B) Urédios vistos ao MEV; C) Urediniósporos com pedicelo vistos ao MEV (seta); D) Urediniósporo com parte apical lisa visto ao MEV (seta); E) Urediniósporo com poro germinativo na região equatorial visto ao MEV (seta). Barras: $A=200$ ìm; $B=10$ ìm; $C=1$ ìm; $D=10$ ìm; $E=1$ ìm. 

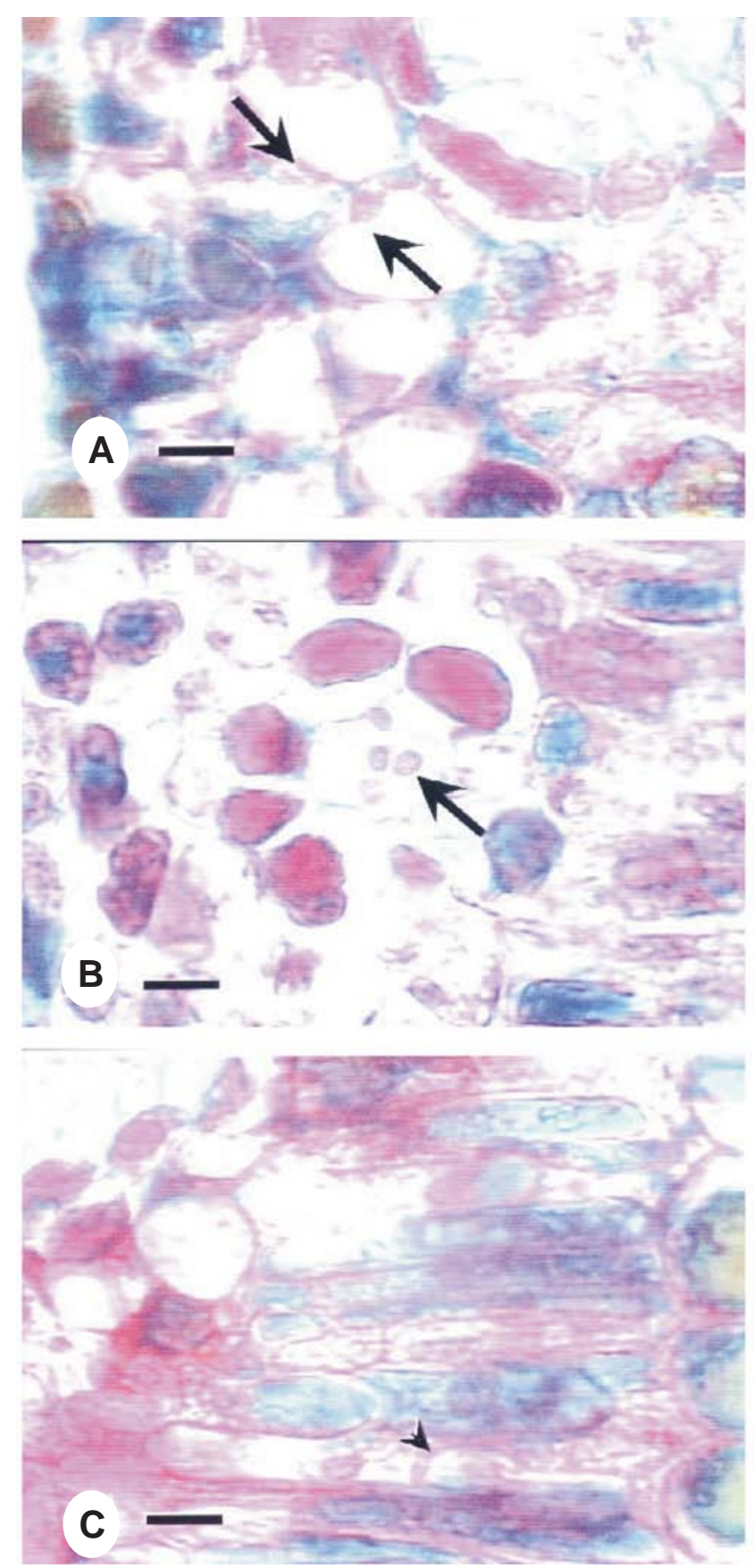

FIG. 4 - Anthomyces brasiliensis. A-B) Haustórios (setas); C; Micélio interno (ponta de seta). Barras: $\mathrm{A}$ a $\mathrm{C}=10$ ìm .

partir de setembro; urédios a partir de dezembro e télios a partir de janeiro.

\section{Distribuição geográfica}

O fungo A. brasiliensis está relatado para os estados do Rio de Janeiro (Dietel, 1899) e Bahia (Bezerra, 2001). Na Bahia foi confirmada a ocorrência do patógeno apenas no município de Porto Seguro. A ocorrência desta espécie na Estação Ecológica de Tapacurá, município de São Lourenço da Mata, PE, é um novo registro para A. brasiliensis.

\section{DISCUSSÃO}

O aumento do cultivo do pau-brasil em viveiros nos últimos anos, para fins ornamentais e de reflorestamento da Mata Atlântica tem levado ao aparecimento de algumas doenças. Do ponto de vista fitopatológico conhecer a biologia, o ciclo de vida e a epidemiologia do patógeno A. brasiliensis, torna-se relevante no sentido de se traçar estratégias de convívio com a doença a fim de minimizar os danos infringidos ao hospedeiro. Nas condições da Estação Experimental Pau-Brasil (CEPLAC), município de Porto Seguro, foi observada alta incidência de manchas foliares causadas por $A$. brasiliensis tanto em viveiros quanto em plantas adultas do arboreto. Com relação à Estação Ecológica de Tapacurá em Pernambuco, como só foi feita uma visita, não foi possível avaliar adequadamente a incidência da doença.

A distribuição geográfica de $A$. brasiliensis não está elucidada. É possível que a espécie ocorra de forma contínua em toda faixa litorânea que vai do Rio de Janeiro a Pernambuco ou mesmo em toda área de ocorrência do paubrasil o que só será confirmado através de levantamentos realizados com tal finalidade. Na Bahia, ainda há a necessidade de levantamentos nas áreas com população nativa de pau-brasil a fim de determinar com segurança a amplitude de sua ocorrência.

Segundo Cummins \& Hiratsuka (2003), a família Raveneliaceae (Arth.) Leppik compreende os gêneros Anthomyces, Anthomycetella, Apra, Cystomyces, Diabole, Dicheirinia, Diorchidiella, Diorchidium, Kernkampella, Lipocystis, Ravenelia, Sphenospora, Spumula, e Ypsilospora. A família é descrita como possuindo espermogônios dos tipos 5 e 7, grupo VI, o estádio ecidiano do tipo Aecidium ou Uraecium, os urédios com ou sem paráfises e urediniósporos equinulados. Os télios com ou sem paráfises e teliósporos pedicelados com dois ou mais esporos apicais dispostos radialmente no topo do pedicelo. As espécies são autóicas e os hospedeiros geralmente são da família Fabaceae. O gênero tipo é Ravenelia Berkeley.

Cummins e Hiratsuka (2003), ressaltam a afinidade entre os gêneros Anthomyces Dietel, Anthomycetella H. \& P. Sydow e Dicheirinia Arthur. O pedicelo dos teliósporos é a característica morfológica mais marcante na diferenciação dos gêneros Anthomyces e Anthomycetella. No gênero Anthomycetella o pedicelo é multihifal enquanto no gênero Anthomyces é unihifal. Esta característica pedicelo simples com uma célula apical para cada esporo é compartilhada com o gênero Dicheirinia, porém os teliósporos de Anthomyces são lisos e os de Dicheirinia são ornamentados, o que diferencia os dois gêneros. Cummins \& Hiratsuka (2003) destacaram a semelhança entre os gêneros afirmando que se fossem encontrados espermogônios do tipo 7 e écios uredinóides em Anthomyces, este gênero seria praticamente igual a Dicheirinia. No entanto, a ornamentação dos 


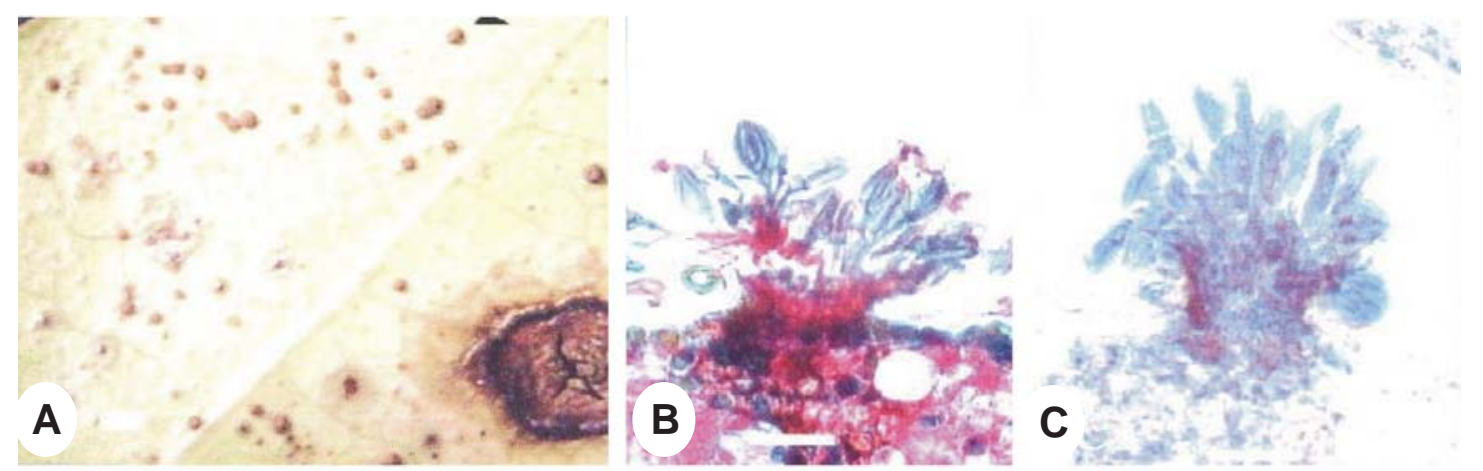

FIG. 5 - Anthomyces brasiliensis. A) Télios ao microscópio estereoscópico; B-C) Secções transversais de télios. Barras: $\mathrm{A}=200$ ìm; B e C = 50 ìm.

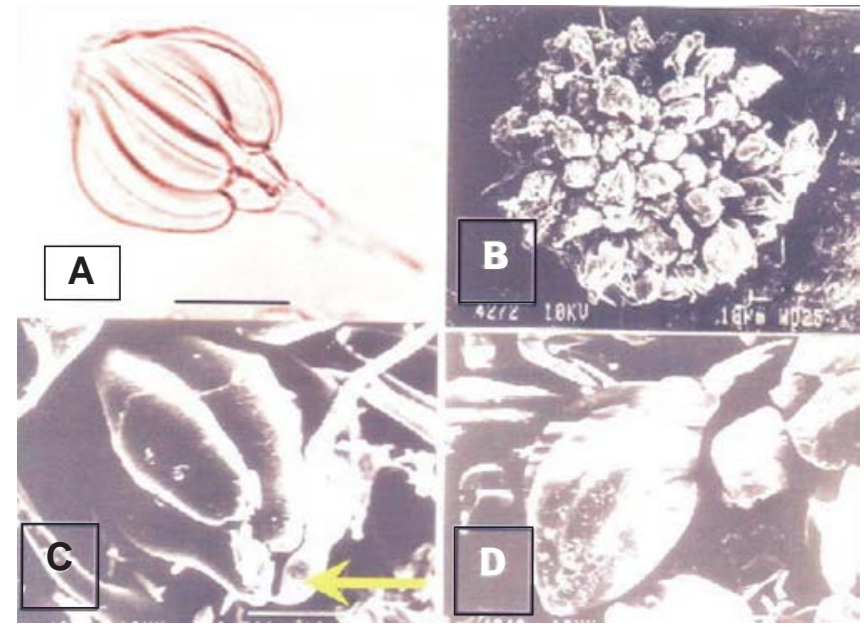

FIG. 6 - Anthomyces brasiliensis. A) Teliósporo ao microscopio ótico; B) Télio visto em MEV. C. Teliósporo com poro germinativo apical (seta); D) Teliósporos fortemente unidos formando capítulo pedicelado, MEV. Barras: A a D = 10 ìm.

teliósporos, e a forma das paráfises são características suficientes para separar os dois gêneros.

\section{AGRADECIMENTOS}

À Profa. Denise Vilela de Rezende Santiago pela orientação nos trabalhos de microscopia eletrônica de varredura. Ao CNPq pela concessão das bolsas de estudo. À CEPLAC pela disponibilização dos laboratórios, veículos e motoristas para a realização dos trabalhos. À Universidade Federal de Brasília por ter viabilizado os estudos em microscopia eletrônica de varredura. Ao Dr. Markus Scholler, ex-curador do Arthur's Herbarium da Universidade de Purdue, pelo empréstimo do espécime tipo de $A$. brasiliensis.

\section{REFERÊNCIAS BILIOGRÁFICAS}

ALEXOPOULOS, C.J., MIMS, C.W. \& BLACKWELL, M. Introductory Mycology $4^{a}$ ed., John Wiley \& Sons, Inc., 1996.

ANON. Conservation and manegement of pau-brasil, Caesalpinia echinata - An action plan. Fauna and Flora International (UK), Botanical gardens of Rio de Janeiro (Brasil), Margaret Mee Foundation (Brasil). (Unpublished report).1997.

BEZERRA, J.L. \& COSTA, J.. Anthomyces brasiliensis parasitando folhas de Pau-Brasil, na Bahia. Fitopatologia Brasileira 314:351-352. 2001.

BRUZESSE, E. \& HASAN, S. A whole leaf clearing and staining technique for host specifity studies of rust fungi. Plant Pathology 32:335-338. 1983.

CUMMINS, G.B. \& HIRATSUKA, Y. Illustrated Genera of Rust Fungi. Revised edn. The American Phytopathological Society of Minnesota U.S.A. 1959.

CUMMINS, G.B. \& HIRATSUKA, Y. Illustrated Genera of Rust Fungi. Revised edn. The American Phytopathological Society of Minnesota U.S.A. 2003.

DIETEL, P. Uredineae brasilienses, a cl. E. Ule lectae. II. Hedwigia 38:248-246. 1899.

GRAMACHO, K.P. Disease resistance and pathogenic variability in the fusiform rust-slash pine pathosystem (PhD. Thesis). University of Florida, Gainnesville. 1999.

GRANDI, R.A. \& SILVA, T.V. Hyphomycetes sobre folhas em decomposição de Caesalpinia echinata Lam.: ocorrências novas para o Brasil. Revista Brasileira de Botânica 6:489-493. 2003.

IBAMA. Lista oficial de espécies da flora Brasileira ameaçadas de extinção. (unpublished). 4pp. Sociedade Botânica do Brasil. Centuria plantarum Brasiliensium extintionis minitata. Sociedade Botânica do Brasil. 1992. p.175.

KIRK, P.M., CANNON, P.F. \& STALPERS, P.A. Dictionary of the Fungi, $9^{\mathrm{a}}$ edition, CABI Bioscience, 2001.

LORENZI, H. Árvores brasileiras. Manual de identificação e cultivo de plantas arbóreas nativas do Brasil/ Nova Odessa, SP: Editora Plantarum 1992. 